NASA Technical Memorandum 102289

\title{
Channelized Coplanar Waveguide Pin-Diode Switches
}

G.E. Ponchak

Lewis Research Center

Cleveland, Ohio

and

R.N. Simons

Case Western Reserve University

Cleveland, Ohio

November 1989 

CHANNELIZED COPLANAR WAVEGUIDE PIN-DIODE SWITCHES

\author{
G.E. Ponchak \\ National Aeronautics and Space Administration \\ Lewis Research Center \\ Cleveland, Ohio 44135 \\ and \\ R.N. Simons* \\ Case Western Reserve University \\ Cleveland, Ohio 44106
}

SUMMARY

Three different types of $p-i-n$ diode, reflective CPW switches are presented. The first two switches are the series and the shunt mounted diode switches. Each has achieved greater than $15 \mathrm{~dB}$ of isolation over a broad bandwidth. The third switch is a narrow band, high isolation switched filter which has achieved $19 \mathrm{~dB}$ of isolation. Equivalent circuits and measured performance for each switch is presented.

\title{
INTRODUCTION
}

Coplanar waveguide, CPW, on a dielectric substrate consists of a center strip conductor with semi-infinite ground planes on either side (ref. 1). Channelized coplanar waveguide, CCPW, consists of CPW transmission line placed in a metal enclosure (ref. 2). Because the ground planes and the center conductor are on the same side of the substrate, shunt as well as series mounting of circuit components can be done without the need for wraparounds or viaholes. The improvements in circuit yield and the reduction in inductance for ground paths over microstrip based circuits should permit microwave integrated circuits, MIC's, to be fabricated at higher frequencies and less expensively. However, the extent of applications of CPW circuits is limited due to the unavailability of circuit elements and models which can be incorporated into CAD programs.

Microwave switches are a basic circuit element for phase shifters and radiometers. A CPW switchable attenuating medium propagation, SAMP, switch has been demonstrated by Fleming et al. (ref. 3). This device is useful for GaAs MMIC circuits but it is not easily incorporated into MIC's on Dassive substrates such as alumina or duroid. P-i-n diodes are good microwave switches since the impedance of the diode can be changed from a very high value to nearly zero in a short time (refs. 4 and 5 ).

This paper presents for the first time CPW $D-i-n$ diode, reflective switches. Three basic switches are presented. The first is a shunt mounted diode switch. This switch is similar to fin line shunt mounted diode switches (ref. 4). The second switch is a series mounted diode across a gap in the center strip conductor. The last switch is a novel design which converts a CPW interdigital coupler with bandpass filter characteristics into a spurline, bandstop filter.

* NASA Resident Research Associate at Lewis Research Center. 
The three switches have been fabricated on CCPW transmission lines. All of the circuits have been fabricated on RT/Duroid 5880 substrates with Metelics corporation beam lead diodes, MBP-1030-B11. Figure 1 is the equivalent circuit

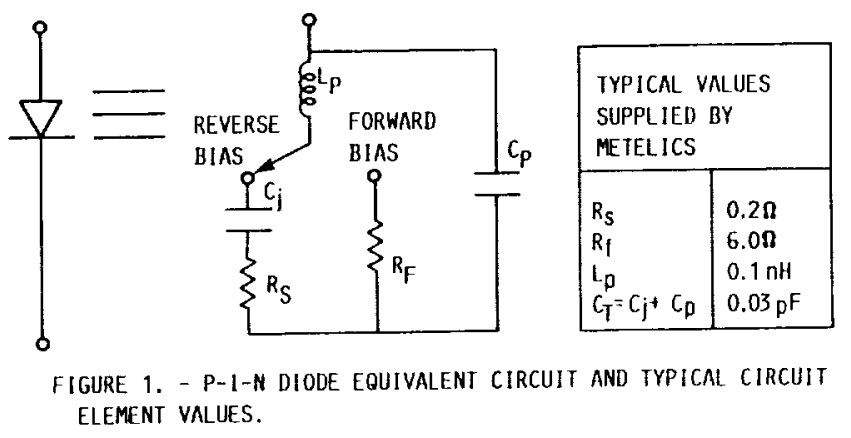

of the diode with the circuit element values supplied by Metelics. Although no tuning to resonate off the diode parasitics was done, the CPW slots were made equal to the length of the packaged diode to minimize the package inductance, Lp. Testing of the switches has been done on an HP 8510 automatic network analyzer with bias tees to supply the dc bias to the diodes. The test fixture is comprised of a 2 in. length of CCPW with a 0.045 in. center strip and 0.010 in. slot. Connection to $3.5 \mathrm{~mm}$ coax cables is made through a pair of coaxial connectors. Tuning notches in the ground plane have been used to improve the coax-to-CCPW characteristics over selected frequency bands. The test fixture has a total insertion loss of $0.5 \mathrm{~dB}$ and a return loss greater than $15 \mathrm{~dB}$ for the frequencies reported in this paper.

\section{P-I-N DIODE SHUNT SWITCH}

In a shunt mounted configuration, a pair of diodes are placed in parallel across the slots of the CCPW transmission line (fig. 2 ). When the diodes are

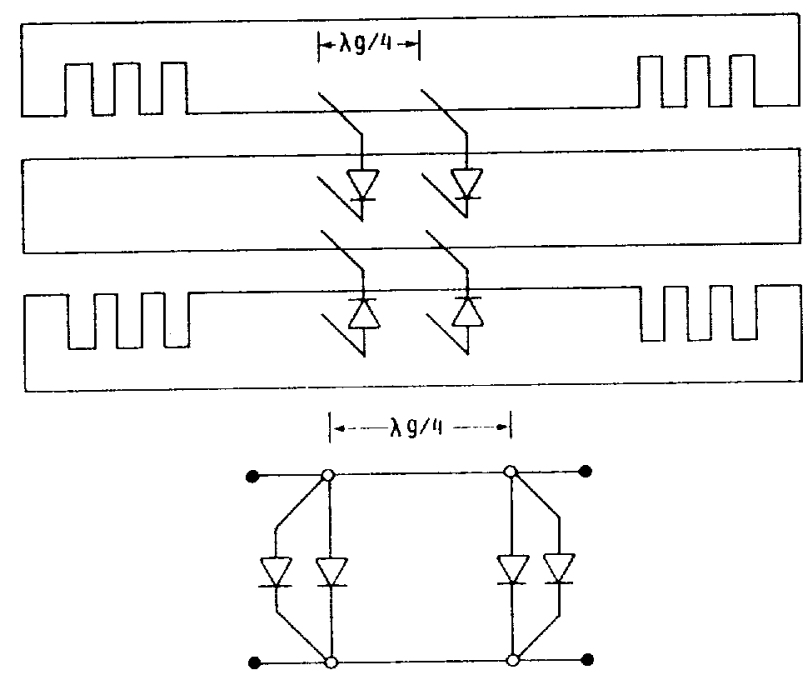

FIGURE 2. - SCHEMATIC AND EQUIVILENI CIRCUIT OF CPW P-I-N DLODE SHUNT SWITCH. 
forward biased, each slot is loaded by the forward bias impedance of the diode; at $10 \mathrm{GHz}$, the impedance across the slot is approximated by $R f+j \omega L p \approx 8.7 \Omega$ < Zo. The shunt impedance for CPW, with two parallel slots, is therefore $4.35 \Omega$. This low impedance loading the slot reflects the propagating wave. When the diode is reverse biased, each slot is loaded by an impedance approximated by $1 /(j \omega C t) \approx 530 \Omega \gg 20$. This is an equivalent shunt impedance of $265 \Omega$ for CPW. This load results in a small attenuation. Using expressions by Watson (ref. 6) modified for two parallel shunt elements, an isolation of $16 \mathrm{~dB}$ and an insertion loss of $0.04 \mathrm{~dB}$ is predicted.

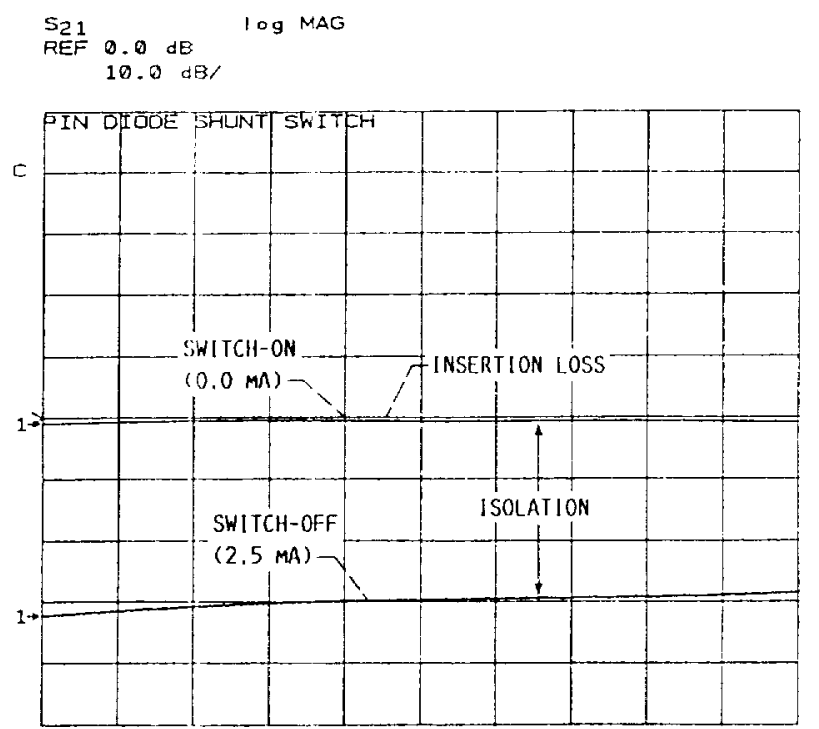

(a) MEASURED INSERTION LOSS AND ISOLATION.

$$
\begin{aligned}
& \text { S11 } \\
& \text { REF } 0.0 \mathrm{~dB} \\
& 10.0 \mathrm{~dB} /
\end{aligned}
$$

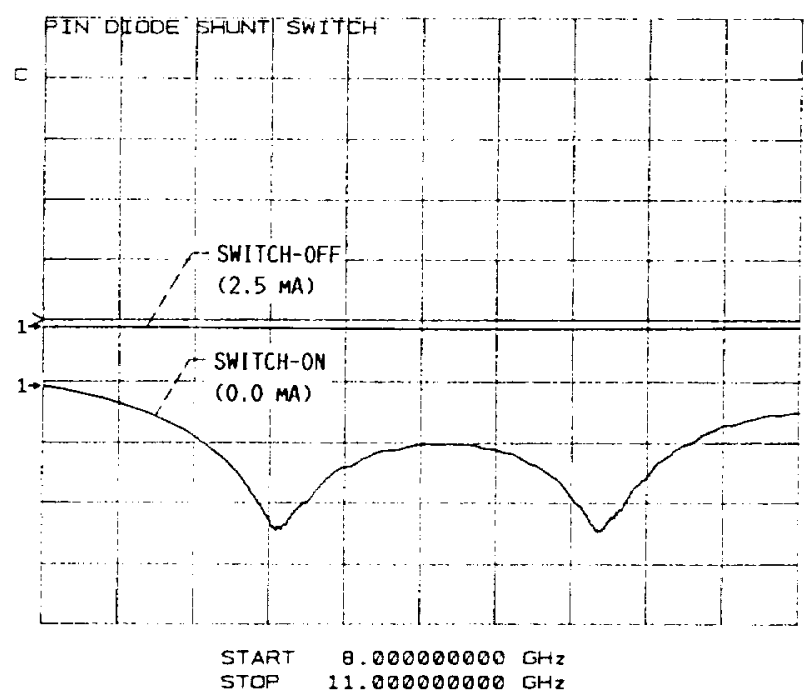

(b) MEASURED RETURN LOSS.

FIGURE 3. - CPW P-I-N DIODE SHUNT SWITCH WITH TWO PAIRS OF DIODES. 
An insertion loss less than $1 \mathrm{~dB}$ and an isolation of 15 dB has been measured over the frequency band of 8 to $11 \mathrm{GHz}$. The return loss was less than $10 \mathrm{~dB}$ across the band. By incorporating more than one pair of diodes across the slots with a $\lambda g / 4$ separation, higher isolation can be achieved. Typically, two pairs of diodes have resulted in an isolation of $30 \mathrm{~dB}$ over the 8 to 11 GHz frequency band with little increase in insertion loss, this is shown in figure $3(a)$. Figure $3(b)$ shows the return loss which is less than $10 \mathrm{~dB}$ across the band.

\section{P-I-N DIODE SERIES SWITCH}

In the series mounted diode configuration, a diode is mounted across an $0.008 \mathrm{in}$. gap in the center strip conductor of the CCPW line (fig. 4). The

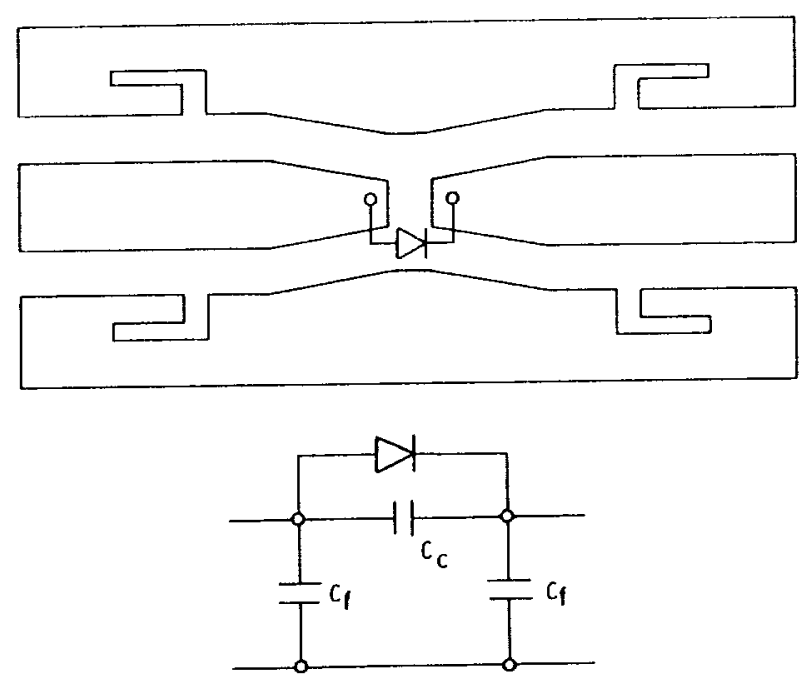

FIGURE 4. - SCHEMAIIC AND EQUIVLENT CIRCUIT OF CPH P-I-N IIODE SERIES SWITCH.

center strip has been tapered to the width of the beam lead diode to provide a better match to the width of the diode package. The gap appears as an equivalent capacitive $\pi$ network (ref. 7 ). When the diode is forward biased, the coupling capacitance is shorted by the low diode impedance and the wave is transmitted. Reverse biasing the diode results in an impedance across the gap which can be approximated by $1 /[j \omega(C t+C c)] \gg 20$ at $10 \mathrm{GHz}$. Therefore, the propagating signal is reflected as if from an open circuit. A measured insertion loss of $1 \mathrm{~dB}$ and an isolation of $15 \mathrm{~dB}$ has been obtained from 0.045 to $8 \mathrm{GHz}$ ( $\mathrm{fig} .5(\mathrm{a})$ ). The return loss over this band is less than $10 \mathrm{~dB}$ (fig. $5(\mathrm{~b})$ ). The gap impedance is not large enough at higher frequencies to provide good isolation. The gap can be lengthened to decrease cc but the increase in inductance from the longer diode leads will ultimately limit the gap separation. Resonating out these reactances is required for higher frequency operation (ref. 5 ). 

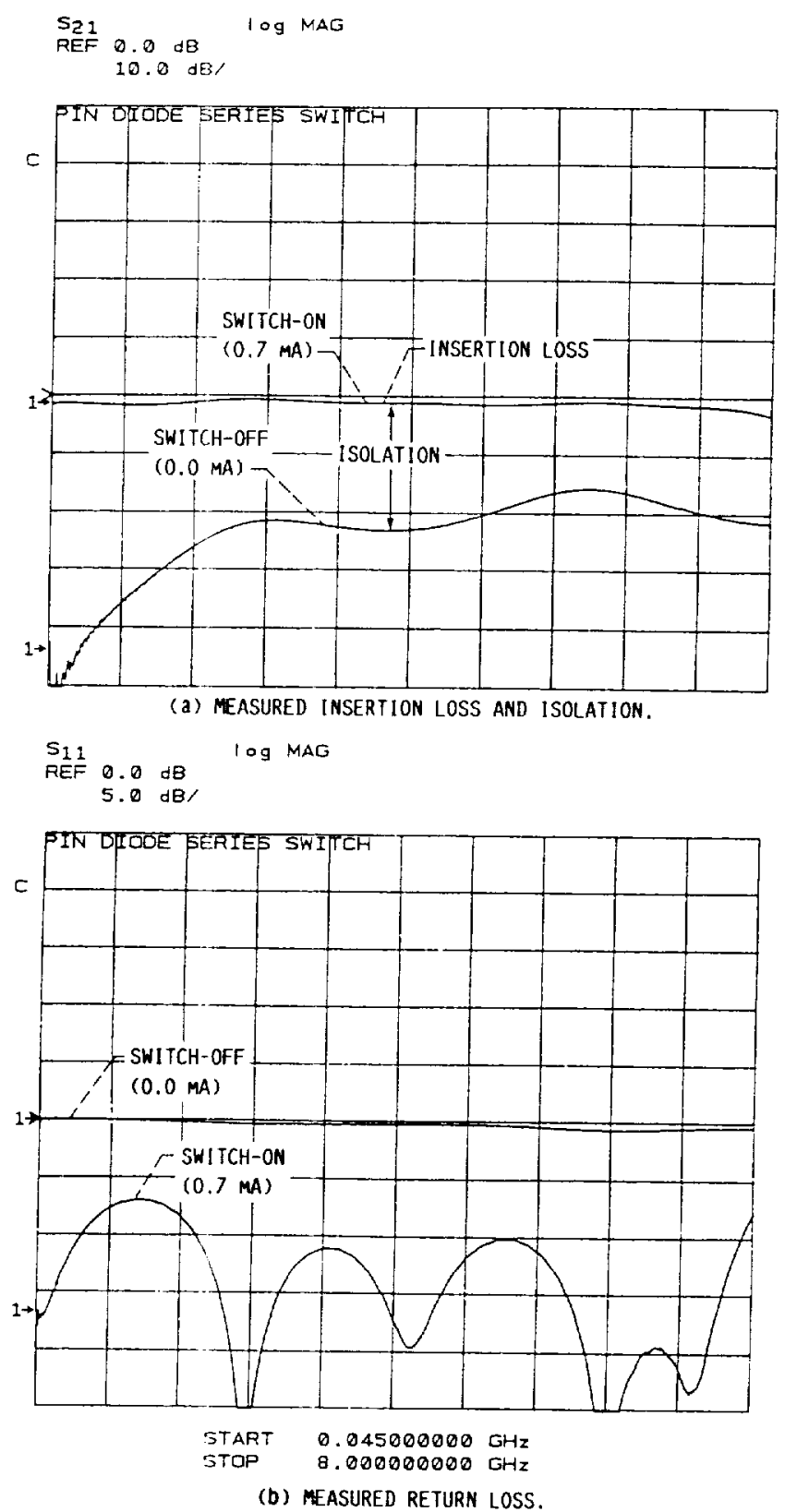

FIGURE 5. - CPW P-I-N DIODE SERIES SHITCH.

\section{P-I-N DIODE SPDT SWITCH}

To realize a SPDT switch, a CCPW Tee-junction with gaps in the center strip conductor at the junction was formed ( $f$ ig. 6). Diodes were mounted across the gaps in parallel. As shown in figure 7 , the measured insertion loss is $1 \mathrm{~dB}$ and the isolation is greater than $15 \mathrm{~dB}$ over the octave bandwidth of 2.25 to $5.5 \mathrm{GHz}$. The return loss was less than $10 \mathrm{~dB}$. 

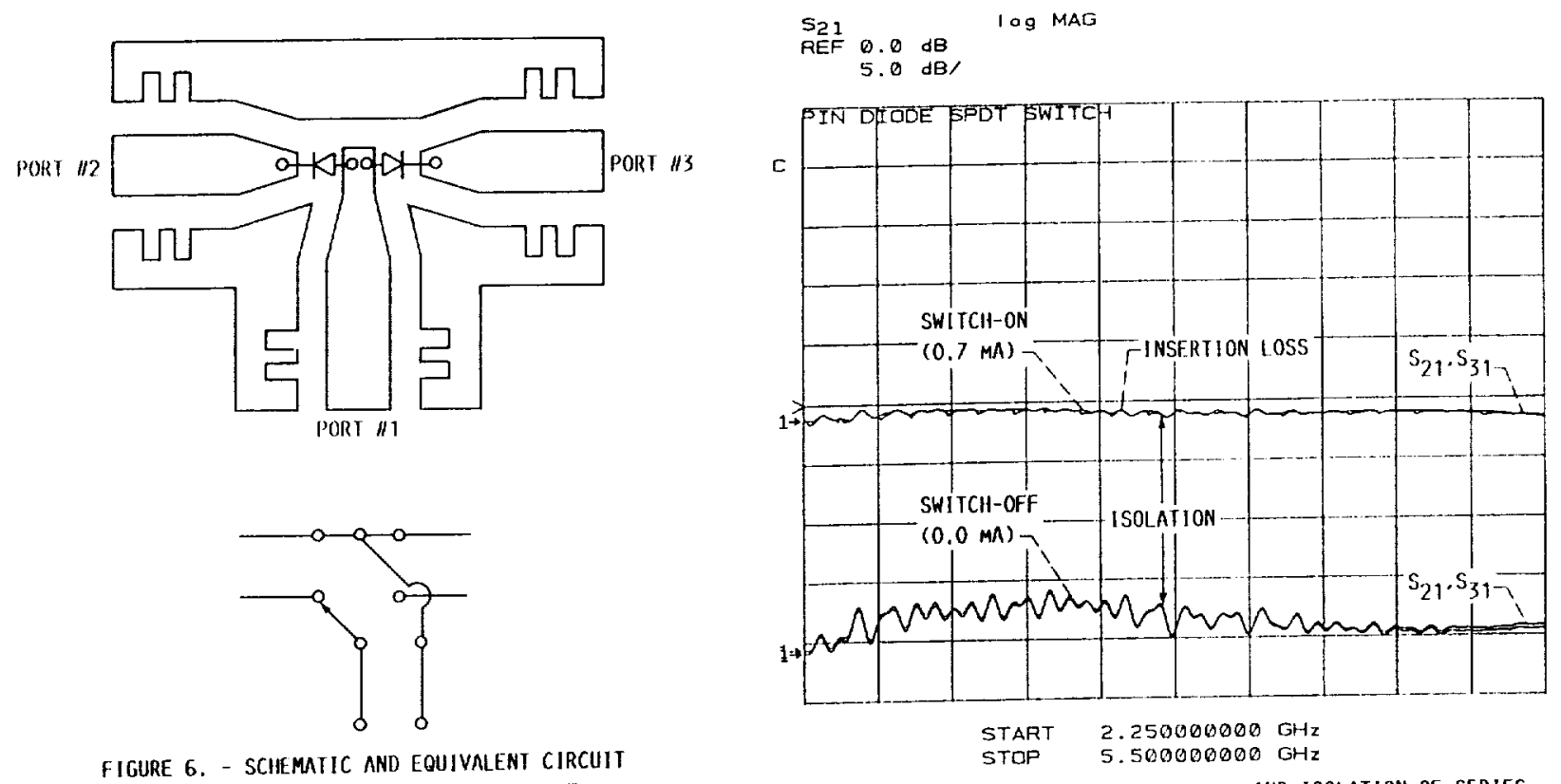

FIGURE 6. - SCHEMAIIC AND EQUIVALENI CIRCUHT OF SERIES MOUNTED P-I-N DIOIE CPW SPDT SWITCH.

FIGURE 7. - MEASURED INSERIION LOSS AND ISOLATION OF SERIES MOUNTED PIN DIODE CPW SPDT SWITCH.

\section{P-I-N DIODE SWITCHED-SERIES-STUB SWITCH}

A diode is mounted across the open end of a $\lambda g / 4$ stub which is in series with the center strip conductor of the CCPW as shown in figure 8 . When the diode is unbiased, the stub is terminated in an effective open circuit and therefore appears as a series short circuit. Hence, the wave propagates with negligible attenuation. This is the on-state of the switch. When the diode is forward biased, the stub is terminated in an effective short circuit which
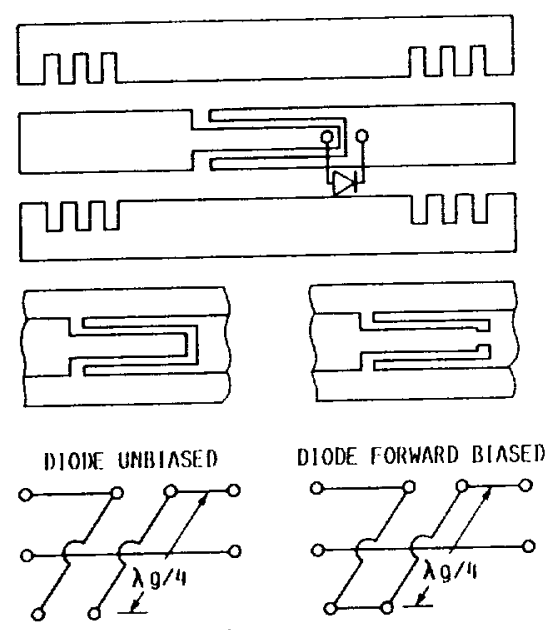

FIGURE 8. - SCHEMATIC AND EQUIVALENT CIRCUIT OF CPW P-I-N DIODE SHITCIEDSERIES-STUB SWITCH. 
therefore appears as a series open circuit. The wave is therefore reflected; this is the off-state of the switch. The diode reactances result in an effective lengthening of the stub and can easily be compensated for. A measured insertion loss of $1.0 \mathrm{~dB}$ and an isolation of $19 \mathrm{~dB}$ has been obtained at $9 \mathrm{GHz}$ (fig. $g(a)$ ). Figure $g(b)$ shows the return loss.

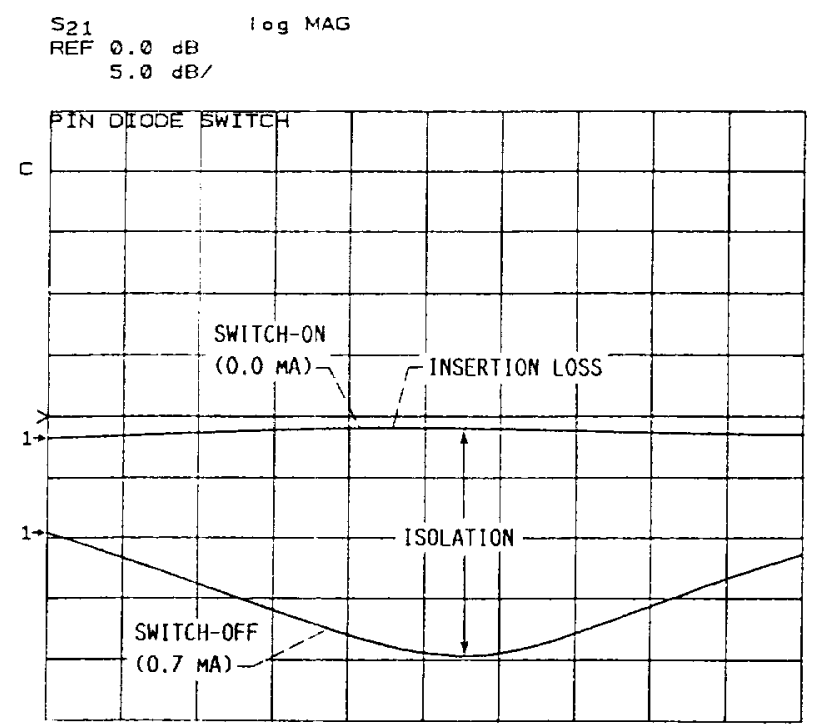

(a) MEASURED INSERTION LOSS AND ISOLATION.

$$
\begin{aligned}
& \text { S11 } \\
& \text { REF } 0.0 \mathrm{~dB} \text { log MAG } \\
& 5.0 \mathrm{~d} 8,
\end{aligned}
$$

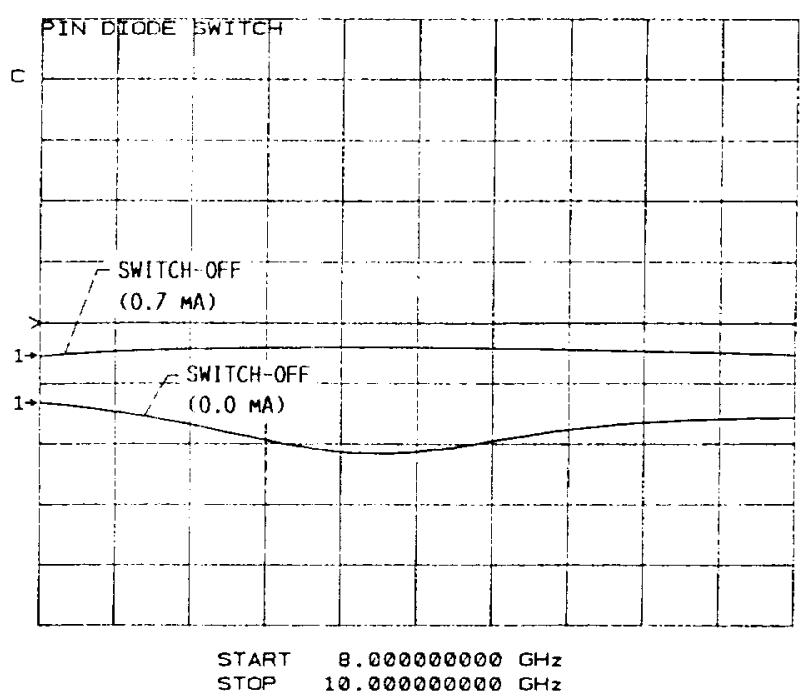

(b) MEASURED RETURN LOSS.

FIGURE 9. - CPW P-I-N DIODE SWITCHED-SERIES-STUB SHITCH.

\section{CONCLUSIONS}

P-I-N diode reflective switches are easily realizable on CCPW transmission line and therefore CPW transmission line. Each of the three type of switches presented are practical for specific applications. The performance of the 
switches could be improved through typical tuning of the diode reactances once the necessary CPW circuit models become available.

\section{REFERENCES}

1. Wen, C.P., "Coplanar Waveguide, A Surface Strip Transmission Line Suitable for Nonreciprocal Gyromagnetic Device Applications," 1969, IEEE Trans. Microwave Theory Tech., vol. MTT-17, pp. 1087-1090.

2. Simons, R.N., Ponchak, G.E., Martzakl is, K.S., and Romanofsky, R.R., "Channelized Coplanar Waveguide: Discontinuities, Junctions, and Propagation Characteristics,: 1989, IEEE MTT-S International Microwave Symposium Digest, IEEE, Piscataway, NJ, pp. 915-918.

3. Fleming, P.L., Smith, T., Carlson, H.E., and Cox, W.A., "GaAs SAMP Device for Ku-Band Switching," ig79, IEEE Trans. Microwave Theory Tech., vol. MTT-27, pp. 1032-1035.

4. Bhat, B., and Koul, S.K., Analys is, Design and Applications of Fin Lines, Artech House, Norwood, MA, 1987.

5. White, J.F., Microwave Semiconductor Engineering, Van Nostrand Reinhold Co., New York, 1982 .

6. Watson, H.A., Microwave Semiconductor Devices and Their Circuit Applications, McGraw-Hill Book Company, New York, 1969.

7. Simons, R.N., and Ponchak, G.E., "Modeling of Some Coplanar Waveguide Discontinuities," IEEE Trans. 1988, Microwave Theory Tech., vol. MTT-36, pp. 1796-1803. 


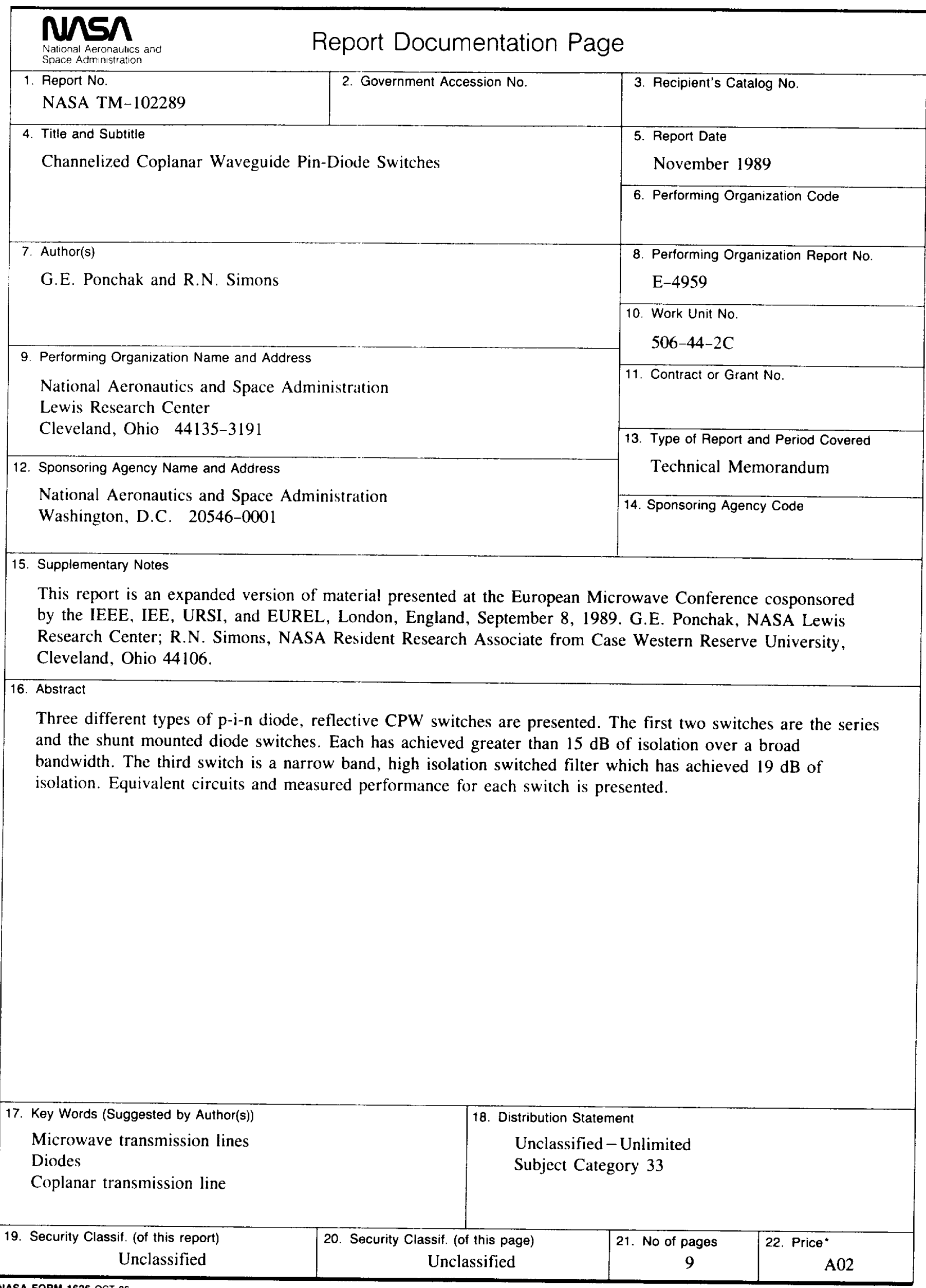


